\title{
Why do mothers die? A retrospective analysis of maternal mortality over 7 years in a tertiary care teaching Hospital in North Karnataka, India
}

\author{
Rajasri G. Yaliwal, Aruna M. Biradar*, Shreedevi S. Kori, \\ Subhashchandra R. Mudanur, Shivakumar U. Pujeri, Jada Sushmita
}

Department of Obstetrics and Gynaecology, BLDE (DU) Shri BM Patil Medical College, Hospital and Research Centre, Vijayapura, Karnataka, India

Received: 16 October 2020

Accepted: 22 October 2020

*Correspondence:

Dr. Aruna M. Biradar,

E-mail: aruna.biradar@bldedu.ac.in

Copyright: (C) the author(s), publisher and licensee Medip Academy. This is an open-access article distributed under the terms of the Creative Commons Attribution Non-Commercial License, which permits unrestricted non-commercial use, distribution, and reproduction in any medium, provided the original work is properly cited.

\section{ABSTRACT}

Background: Maternal mortality ratio (MMR) is still high in many developing countries. In Southern India, the maternal mortality is highest in the state of Karnataka. Therefore, a study was conducted at BLDE (DU) Shri BM Patil medical college, hospital and research centre to study the causes of maternal deaths, and to make recommendation to reduce the maternal mortality.

Methods: A retrospective analysis of all the maternal deaths between 2012 to 2019 was done.

Results: A total of 58 women died due to pregnancy and its complications during the period of 2012-2019. Average age of death was 25.42 years. It was noted that $70.7 \%$ of the patients travelled over $30 \mathrm{~km}$ to reach Vijayapura city. The predisposing causes of death were post-partum haemorrhage $(44.8 \%)$ eclampsia $(18.9 \%)$, anaemia $(17.2 \%)$, pulmonary or amniotic fluid embolism (12.1\%), sepsis (10.3\%) antepartum haemorrhage (3.4\%) and cardiac disease $(6.9 \%)$. A death each occurred in patients suffering cholestasis and adult respiratory distress syndrome. A majority of the deaths were post-partum deaths (84\%). Most of the deaths of the occurred during the first 12 hours of admission (82.76). A total of 11 patients received blood and blood components. Of the 58 deaths, 56(96\%) required ventilatory support., $47(81 \%)$ patients received ionotropic support. $11(19 \%)$ patients underwent peripartum hysterectomy.

Conclusions: Timely intervention can save maternal lives. Services of well-equipped hospitals with obstetric intensive care units having a dedicated team of well-trained obstetricians, intensivists and anaesthesiologist are recommended in a facility which is near the residence of the pregnant women. Facilities for quick transfer of the cases who are high risk are required.

Keywords: Maternal mortality, Postpartum eclampsia, Sepsis, Blood transfusion, Intensive care unit

\section{INTRODUCTION}

Maternal mortality is a devastating loss to the family. According to the world health organisation (WHO), in 2017 about 810 women died every day worldwide due to pregnancy and childbirth. ${ }^{1}$ Most of the causes of maternal mortality are preventable. Between 2000 and 2017, the global maternal mortality ratio (MMR, number of maternal deaths per 100,000 live births) dropped to 211 in 2017 from 342 in 2000 which accounts for $38 \%$ reduction in the MMR. Income wise distribution of the maternal deaths show that $94 \%$ of all maternal deaths occur in low and lower middle-income countries. Maternal mortality is considered low if the MMR less than 100, moderate if it is between 100-299, high if it is 300-499, very high if it is 500-999 and extremely high if it is greater than or equal to 1000 maternal deaths. Nigeria and India had the highest estimated numbers of maternal deaths, accounting for approximately one third $(35 \%)$ of estimated global maternal deaths in 2017 , with 
India responsible for $12 \%$ of the total global maternal deaths.

WHO defines maternal death as the death of a woman while pregnant or within 42 days of termination of pregnancy, irrespective of the duration and site of the pregnancy, from any cause related to or aggravated by the pregnancy or its management but not from unintentional or incidental causes. ${ }^{1}$

The target of sustainable development goals (SDG) set by the United Nations aims to have MMR less than 70 by the year 2030. India has an MMR of 113 with the empowered action group (EAG) states comprising Bihar, Jharkhand, Madhya Pradesh, Chhattisgarh, Odisha, Rajasthan, Uttar Pradesh and Uttarakhand and Assam states averaging 162. Of the southern states, Karnataka has been the worst performer with a MMR of 97, while the MMR of other southern states are, Telangana - 76, Andhra Pradesh -74, Tamilnadu - 63 and Kerala- 42. ${ }^{2}$

In Karnataka, the districts of Koppal, Ballari, Vijayapura, Raichur and Yadgir have higher MMR. Various health scheme directed towards maternal and child health like thayi bhagya, thayi bhagya plus, prasuthi araike, janani suraksha yojana and janani shishu suraksha karyakrama. have helped in reducing the MMR but at a slow pace. ${ }^{3}$

Hence a study to analyses the potential areas of improvement in the approach to pregnancy as a whole was required to reduce the maternal mortality in region.

Objectives of the study were to analyses the cause of maternal deaths in pregnant women attending BLDE (DU) Shri BM Patil medical college hospital and research centre Vijayapura, North Karnataka, to study the preventable causes of maternal deaths in association to time from developing the complication to time of admission to the hospital and time of admission to time of death of the woman and make recommendations to reduce the maternal mortality.

\section{METHODS}

Source of data from all pregnant women who died at BLDE (DU) Shri BM Patil medical college, hospital and research centre, Vijayapura, Karnataka, India, who died either during antepartum, intrapartum or postpartum period. Post-partum deaths were taken till 42 days after the delivery. The medical college hospital is the only hospital which has 24/7 obstetric services with obstetric intensive care unit, blood bank and well-equipped hospital in the entire district.

For collection of data a retrospective study was conducted and all maternal deaths between 2012 to 2019 were analysed. A data collecting instrument in the form of proforma was designed to collect the data from the case sheets of the deceased patients.
Inclusion criteria included all pregnant women who died at BLDE (DU) Shri BM Patil medical college hospital and research centre, till 42 days following delivery and place of delivery being both in and out of BLDE (DU) Shri BM Patil medical college, hospital and research centre.

Exclusion criteria excluded any maternal death after 42 days from date of delivery and any death caused due to accident or reasons not attributable to medical cause directly or indirectly.

Study variables included data regarding the age, gravidity, details of antenatal care, distance travelled by the woman from her residence, stage of pregnancy at which the woman presented, time of onset of the complication and time of admission, time of admission to death, predisposing factor for death of the patient, requirement of ventilatory support, inotropes, blood and blood components were taken and analysed.

Statistical analysis carried out by categorical variables were presented as frequency (\%).

Ethical clearance was obtained from the institutional ethics committee, BLDE (Deemed to be university) IEC: BLDE (DU)/IEC/442/2020-21.

\section{RESULTS}

A total of 58 women died due to pregnancy and its complications during the period of 2012-2019.

Table 1. Distribution of age and other reproductive history parameters of the deceased women.

\begin{tabular}{|lll|}
\hline Variables & $\begin{array}{l}\text { No. of } \\
\text { cases }\end{array}$ & $\begin{array}{l}\text { Percentage } \\
(\%)\end{array}$ \\
\hline Age (years) & & \\
\hline $18-22$ & 16 & 27.59 \\
\hline $23-27$ & 25 & 43.10 \\
\hline $28-32$ & 13 & 22.41 \\
\hline $33-37$ & 3 & 5.17 \\
\hline $38-42$ & 1 & 1.72 \\
\hline Other parameters & & \\
\hline Primigravida & 30 & 51.72 \\
\hline Multigravida & 29 & 48.28 \\
\hline Antepartum deaths & 9 & 15.52 \\
\hline Postpartum deaths & 49 & 84.48 \\
\hline Booked & 39 & 67.24 \\
\hline Unbooked & 19 & 32.76 \\
\hline
\end{tabular}

\section{Sociodemographic characteristics}

It was noted that $29.3 \%$ of women came from places 30 $\mathrm{km}$ or less from hospital whereas $70.7 \%$ of patients came from places over $30 \mathrm{~km}$ from Vijayapura city (Figure 1). About half women who died were primigravidae. It was 
interesting to note that $67 \%$ of patients had received antenatal care prior to the admission (Table 1).

\section{Main variable results}

The commonest predisposing cause of death was postpartum haemorrhage accounting for $44.8 \%$ of the total deaths, followed by eclampsia (18.9\%), anaemia (17.2\%), pulmonary or amniotic fluid embolism (12.1\%), sepsis $(10.3 \%)$ antepartum haemorrhage $(3.4 \%)$ and cardiac disease $(6.9 \%)$. A death each occurred in patients with cholestasis and ARDS (Figure 2).

Of the patients who had post-partum haemorrhage (PPH) $17(65.4 \%)$ were due to atonic PPH, 3 (11.5\%) were traumatic PPH of which 2 patients had ruptured uterus, 4 $(154 \%)$ were due to adherent/retained placenta and 2 $(7.7 \%)$ were due to coagulation failure (Figure 3 ).

Table 2: Time from complications to admission to death and number of referrals prior to admission and GCS on arrival.

\begin{tabular}{|lll|}
\hline Factors & \multicolumn{2}{l|}{$\begin{array}{l}\text { No. of cases } \\
\text { Time from }\end{array}$ complication to admission (Hours) } \\
\hline $0-6$ & 34 & 58.62 \\
\hline $6.1-12$ & 14 & 24.14 \\
\hline $12.1-24$ & 2 & 3.45 \\
\hline$>24$ & 8 & 13.79 \\
\hline Time of admission to time of death (Hours) \\
\hline $0-6$ & 19 & 32.75 \\
\hline $6.1-12$ & 7 & 12.07 \\
\hline $12.1-18$ & 7 & 12.07 \\
\hline $18.1-24$ & 3 & 5.17 \\
\hline$>24$ & 22 & 37.93 \\
\hline No. of referrals prior to visiting treating hospital \\
\hline 0 & 17 & 29.315 \\
\hline 1 & 34 & 58.62 \\
\hline 2 & 5 & 8.62 \\
\hline 3 & 2 & 3.4 \\
\hline GCS score & & \\
\hline $0-3$ & 15 & 25.86 \\
\hline $3-8$ & 11 & 18.97 \\
\hline $8-15$ & 32 & 55.17 \\
\hline
\end{tabular}

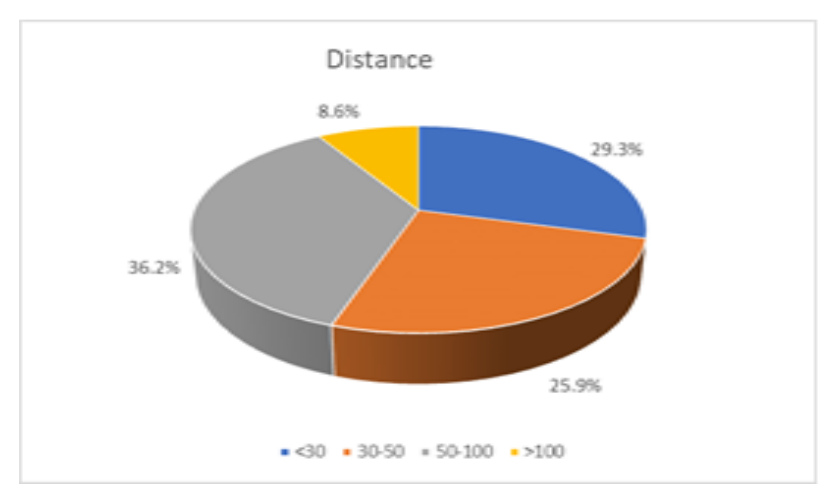

Figure 1: Distance travelled in kilometres by the deceased from her residence to the hospital.

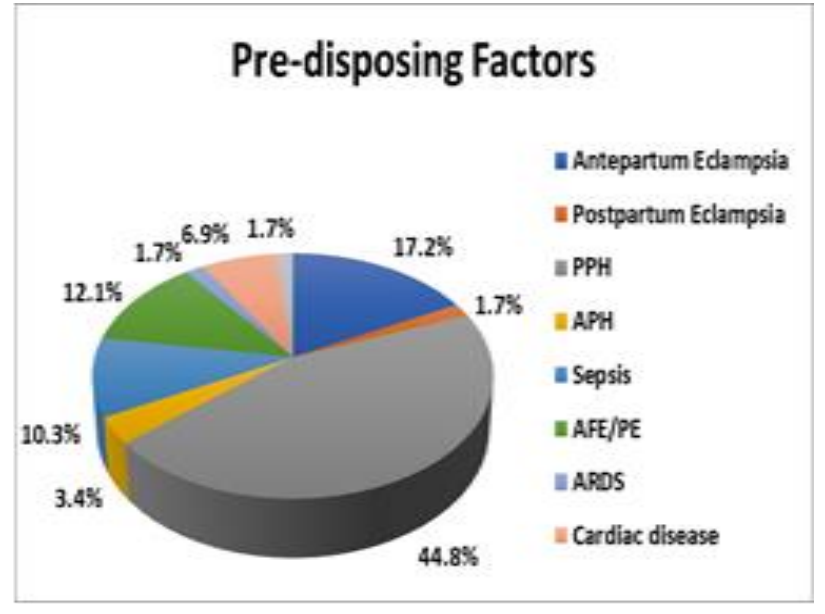

Figure 2: Predisposing factors of maternal mortality.

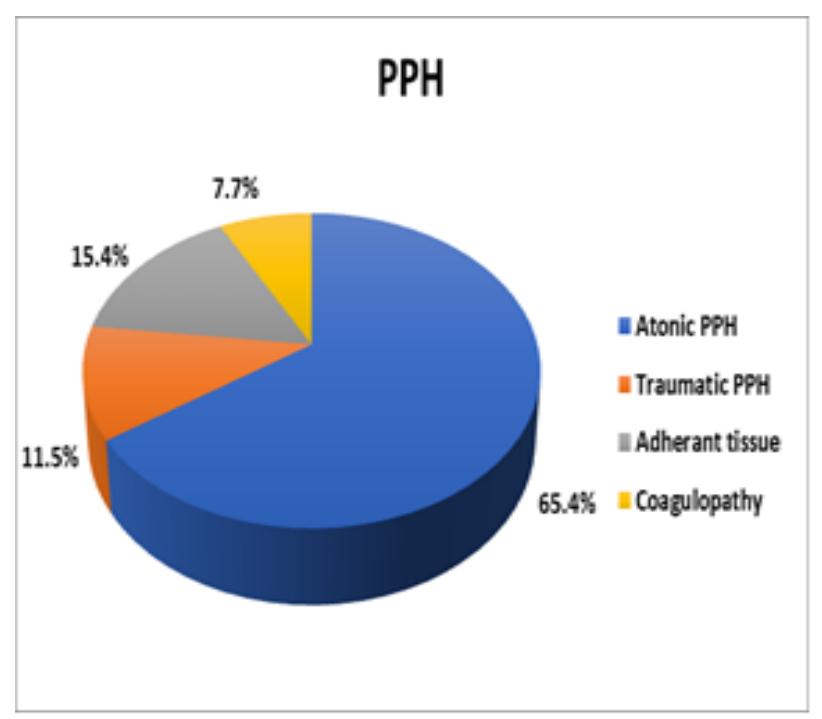

Figure 3: Types of post-partum haemorrhage.

\section{Other variable results}

A majority of the deaths were post-partum deaths (84\%). Most of the deaths of the occurred during the first 12 hours of admission (82.76\%). Almost a third of the patients died within the first 6 hours of developing complications and almost two-thirds by 24 hours. While $29.3 \%$ of the deaths were patients who delivered at the hospital, $70.6 \%$ of the patients were referred from other hospitals for intensive management. In consideration of the condition in which the patients presented to the hospital, 44\% had a Glasgow comma scale (GCS) score of less than 8 and $25 \%$ had a score of less than 3 (Table 2). A total of 11 patients received blood and blood components of which four received packed cell volume $(\mathrm{PCV})$, nine received whole blood, eight received fresh frozen plasma and five received platelets. Of the 58 deaths, $19(32 \%)$ patients required ventilatory support on admission, $37(64 \%)$ received ventilatory support in later stages, $47(81 \%)$ patients received ionotropic support by either dopamine, noradrenaline or dobutamine infusions. $11(19 \%)$ patients underwent peripartum hysterectomy. 


\section{DISCUSSION}

\section{Age}

A total of 58 maternal deaths were analyses. Most of the women were between age 18-32 years, of which the majority were 23-27 years of age. This is due to the fact that this is the reproductive age of most women. The WHO states that there is an association with maternal mortality and teen aged pregnancy. ${ }^{1}$ As marriage is legal at 18 years in India, did not see many teen aged mortalities. Another Indian study reported half the maternal deaths were in the age range of 20-29 years. ${ }^{4}$ In a study conducted in Nigeria, maternal mortality was highest in the age group of $25-34 .^{5}$

\section{Distance travelled by the patient}

The study noted that $70.7 \%$ of the woman had to travel more than $30 \mathrm{kms}$ to reach the hospital. In terms of time, this would equate to over an hour for travel on road and arrangement of logistics. It would also mean than some additional time would be required to arrange transport. In critical cases, the time lost on travel and travel arrangements would have huge impact on the deteriorating health of the woman. Knowing the fact that death can occur in an unattended atonic postpartum haemorrhage by 2 hours, this delay in treatment due to lack of facilities at distant places becomes a major contributing factor to the death of pregnant women. In a study conducted in India, $44 \%$ of the patients could not get transport in time to go to well-equipped hospital after developing complications. ${ }^{5}$ Other studies also show that lack of transport facility and hence delay in treatment contributed to maternal deaths. , $^{5,6}$

\section{Antenatal care}

About two thirds of the women received antenatal care. The quality of care and type of care provider was not documented. Even though the women had taken antenatal care, it did not exempt them from intrapartum or postpartum complications. Most of the deaths were postpartum, indicating the need to recognize the postpartum catastrophe and also to impress upon the pregnant women the need for proper intrapartum and postpartum care. Other national level studies showed that $61.8 \%$ of the women had taken antenatal care. ${ }^{4}$

\section{Predisposing factors of maternal mortality}

Just under half of patients died due to postpartum haemorrhage. In recent report from government of Karnataka, hypertensive disorders of pregnancy were commonest cause of death followed by haemorrhage. Global estimates of predisposing factors for maternal mortality are haemorrhage $27.1 \%$, hypertensive disorders $14.0 \%$, and sepsis $10.7 \%$ of maternal deaths, abortion $7.9 \%$, embolism $3.2 \%$, and other direct causes of death $9.6 \% .^{7}$
A third of the patients died by the first 6 hours of the complication and two thirds by 24 hours. Monitoring the patient for the first 6 hours after delivery is of utmost importance. This shows that swift action is required when complications occur. In a study conducted in Nigeria, $28.9 \%$ of the patients died within the first 6 hours and $51.2 \%$ died by 24 hours.8 Another study conducted in India showed that the maternal mortality was $51.6 \%$ in the first 6 days postpartum. ${ }^{4}$

$70.6 \%$ of the women were treated at different hospitals and were referred to our hospital. In a study conducted in Varanasi, India, $50 \%$ of the patients had visited 2 or more medical centres prior to the hospital at which they died. ${ }^{8}$ In a study conducted in Vijayapura itself, it was observed that $31 \%$ of the patients died during transit. ${ }^{9} 44 \%$ of the women had a GCS score of 8 or less and $25 \%$ were of GSC score 0-3, which suggests that they were very critical on arrival.

Clinical management of the cases. Whole blood, Packed Cell Volume (PCV), fresh frozen plasma (FFP) and platelets were transfused to 11 patients. None of the patients received the standard ratio of transfusion i.e. 1:1:1. This was due to non-availability of adequate blood and blood component. This implies that well equipped blood banks are required for the management of such high-risk cases. Almost a third of the patients required ventilatory support on admission, thereby showing the importance and need of an obstetric ICU. A majority of the patients required ionotropic support. Administration of inotropes require syringe pumps, which are expensive and are not easily available in all set ups. A majority of the patients required ventilatory support. This again impresses the necessity of full-time obstetric ICU in the district. Such ICU facilities are only present in tertiary care centres, and not in taluka level hospitals. The time lost in travel and recognition of the complication are of paramount importance to the outcome of the patient's management. Peripartum hysterectomy was done in 11 patients. This would require an experienced gynaecologist along with a team of expert anaesthesiologists and intensivists.

In India, maternal death review (MDR) started in 2010. Although each maternal death should asses the reasons of death in MDR, only two third are analysed and most of the time it is the cause of death that is discussed rather than the gaps in the health system and the institutional corrective measures. ${ }^{11}$ According to the WHO multicounty survey on maternal and new-born health (WHOMCS), high coverage of essential interventions did not imply that there would be reduction in the maternal mortality. This points to the fact that other factors for maternal mortality have to be considered. ${ }^{12}$

\section{Limitations}

As the study was retrospective, it was difficult to assess the actual time from the complication. 


\section{CONCLUSION}

Comprehensive care during each stage of pregnancy is required for all women. Services of well-equipped hospitals which can treat high risk patients should be available at each taluka. Blood banks with adequate stock of blood and blood components are required. Obstetric intensive care units with dedicated team of well-trained obstetricians, intensivists and anaesthesiologist are recommended in each district. Facilities to quickly transfer patients even from the remote villages to the hospital at the shortest duration of time are necessary. Such facilities are required and should be necessitated without delay to reduce the burden of maternal mortality on the society

\section{Recommendation}

District-wise detail studies of maternal mortality with importance to confidential maternal death reviews and issues regarding the delay in treatments and lack of facility are required.

Funding: No funding sources Conflict of interest: None declared

Ethical approval: The study was approved by the Institutional Ethics Committee with IEC No- [BLDE (DU)/IEC/442/2020-21]

\section{REFERENCES}

1. World Health Organization. (2019). Trends in maternal mortality 2000 to 2017: estimates by WHO, UNICEF, UNFPA, World Bank Group and the United Nations Population Division: executive summary. World Health Organization. Available at: https://apps.who.int/iris/handle/10665/327596.

License: CC BY-NC-SA 3.0 IGO. Accessed on $24^{\text {th }}$ September 2020.

2. Telangana at 'striking distance' from targeted MMR. Available at: https://timesofindia.indiatimes.com/ city/hyderabad/telangana-at-striking-distance-fromtargeted-mmr/articleshow/71974073.cms. Accessed on $24^{\text {th }}$ September 2020.

3. Special Bulletin on Maternal Mortality in India 2016-18. Sample Registration System Office of The Registrar General, India. Vital Statistics Division, New Delhi. 2018;1-3.
4. Montgomery AL, Ram U, Kumar R, Jha P. Million Death Study Collaborators. Maternal mortality in India: causes and healthcare service use based on a nationally representative survey. PLoS One. 2014;9(1):e83331.

5. Sageer R, Kongnyuy E, Adebimpe WO, Omosehin O, Ogunsola EA, Sanni B. Causes and contributory factors of maternal mortality: evidence from maternal and perinatal death surveillance and response in Ogun state, Southwest Nigeria. BMC Pregnancy Childbirth. 2019;19(1):63.

6. Diana S, Wahyuni CU, Prasetyo B. Maternal complications and risk factors for mortality. J Public Health Res. 2020;9:1842.

7. Say L, Chou D, Gemmill A, Tunçalp Ö, Moller AB, Daniels $\mathrm{J}$ et al. Global causes of maternal death: a WHO systematic analysis. Lancet Glob Health. 2014;2(6): e323-33.

8. Kumari K, Srivastava RK, Srivastava M, Purwar N. Maternal Mortality in Rural Varanasi: Delays, Causes, and Contributing Factors. Indian J Community Med. 2019;44(1):26-30.

9. Thobbi VA, Deshpande G, Reddy P. Maternal mortality in Bijapur district. Al Ameen J Med Sci. 2015;8(2):119-24.

10. Sarma UC, Kakoty SD. Maternal mortality: An equity issue. Indian J Public Health 2017;61:231-2.

11. Malhotra M. Maternal Death Review-Country Perspective: Presentation at WHO Multicounty Workshop, Bangkok, Thailand. 24-28 September, 2012. New Delhi: Deputy Commissioner, Maternal Health, MoHFW, Government of India. 2012.

12. Souza JP, Gülmezoglu AM, Vogel J, Carroli G, Lumbiganon P, Qureshi Z et al. Moving beyond essential interventions for reduction of maternal mortality (the WHO Multicountry Survey on Maternal and Newborn Health): a cross-sectional study. Lancet. 2013;381(9879):1747-55.

Cite this article as: Yaliwal RG, Biradar AM, Kori SS, Mudanur SR, Pujeri SU, Sushmita J. Why do mothers die? A retrospective analysis of maternal mortality over 7 years in a tertiary care teaching Hospital in North Karnataka, India. Int J Reprod Contracept Obstet Gynecol 2020;9:4665-9. 